\title{
EL DAÑO MORAL COMO PARTE DE LA RESPONSABILIDAD CIVIL EN EL DERECHO INTERNACIONAL COMPARADO ${ }^{1}$
}

\author{
Eusebio Francisco Tulio Flores Contreras ${ }^{2}$
}

Sumario: I.Introducción.II. Derecho Francés; III.Derecho Español.IV. Derecho Argentino. V.Derecho Cubano; V.Derecho Canadiense (Quebec). VI. Sistema de Common Law. VII.Tratados Internacionales de Derechos Humanos VIII. Conclusiones y Recomendaciones.IX Bibliografía

\section{Resumen}

Este trabajo deriva de la tesis de licenciatura intitulada: "El daño moral como parte de la responsabilidad civil en el Derecho Mexicano y el Derecho Internacional Comparado", tema de una especial aridez, tanto práctico como doctrinariamente; esto derivado de las causas que especifica el legislador para determinar "razonablemente y en equidad" el "quantum numerarium" cantidad económica que tendría que resarcir afectaciones sentimentales, mentales o incluso pérdidas de vida. Labor encomiable del juzgador que tampoco puede ser pitonisa del oráculo de Delfos, para adivinar una reparación del daño moral tal indescifrable. En base al método del derecho comparado y adentrando en las diferentes teorías internacionales para la determinación del daño moral, se examinaron también diferentes instrumentos jurídicos mexicanos y del extranjero sobre la materia de estudio e Igualmente, se analiza diversas resoluciones judiciales dictadas por nuestros tribunales de justicia y algunas sentencias también emitidas en el derecho extranjero para darle una debida conformación al tema. ${ }^{3}$

Palabras clave: Daño moral, Responsabilidad Civil, Derecho Comparado Internacional

\footnotetext{
${ }^{1}$ El presente trabajo es una síntesis del trabajo de investigación presentado para obtener el título de Licenciado en Derecho en la Universidad de Sonora, dirigida por el Maestro Manuel Mercado Amparano y asesorado a la distancia por el Doctor Eusebio Flores Barraza.

${ }^{2}$ Estudiante recién egresado del Programa de Licenciatura en Derecho del Departamento de Derecho,División de Ciencias Sociales,URC Universidad de Sonora

${ }^{3}$ Debo de hacer una especial mención en que, si bien el daño moral puede estudiarse fehacientemente en el ámbito penal, lo que se busca con el presente trabajo es analizarlo desde un punto de vista civilista e internacional. Para ser más exactos en conjunto con la responsabilidad civil, ya que esto fácilmente nos permite tomar ciertos elementos o rasgos a la hora de realizar un análisis comparativo con otras legislaciones y países. De ahí lo sobrante de un análisis penalista.
} 


\section{Abstract}

This work derives from the degree thesis entitled: "Moral damage as part of civil responsibility in Mexican Law and Comparative International Law", the subject of a special aridity, both practical and doctrinally; this derived from the causes specified by the legislator to determine "reasonably and in equity" the "quantum numeration" economic amount that would have to compensate for emotional, mental or even loss of life. Commendable work of the judge who can not be a pythoness of the oracle of Delphi, to guess a repair of such indecipherable moral damage. Based on the comparative law method and entering the different international theories for the determination of moral damage, different Mexican and foreign legal instruments on the subject of study were also examined and Likewise, various judicial resolutions issued by our courts of justice are analyzed and some sentences also issued in foreign law to give due conformance to the subject.

Keywords: Moral damage, Civil Liability, International Comparative Law.

\section{INTRODUCCIÓN}

En este apartado procederemos a tomar diversos instrumentos jurídicos de otros países, para analizar en qué contexto se encuentra el daño moral en el derecho comparado. Para llegar a esto daremos un recorrido por diversos códigos civiles así como por tratados internacionales que nos muestre materia relevante para nuestro tema central de estudio.

\section{DERECHO FRANCÉS.}

Código Civil Francés.

Artículo 9.

Chacun a droit au respect de sa vie privée.

Les juges peuvent, sans préjudice de la réparation du dommage subi, prescrire toutes mesures, telles que séquestre, saisie et autres, propres 
à empêcher ou faire cesser une atteinte à l'intimité de la vie privée : ces mesures peuvent, s'il y a urgence, être ordonnées en référé.

Cada uno tiene derecho a que se respete su vida privada.

Sin perjuicio de la reparación del daño sufrido, los jueces podrán prescribir toda clase de medidas tales como secuestro, embargo y demás, propias para impedir o cesar un ataque a la intimidad de la vida privada; en caso de necesidad estas medidas podrán ordenarse por procedimiento de urgencia.

Artículo 16.

La loi assure la primauté de la personne, interdit toute atteinte à la dignité de celle-ci et garantit le respect de l'être humain dès le commencement de sa vie.

La ley asegura la primacía de la persona, prohíbe cualquier ataque a su dignidad y garantiza el respeto del ser humano desde el comienzo de su vida.

Artículo 16-1.

(Chacun a droit au respect de son corps.

Le corps humain est inviolable.

Le corps humain, ses éléments et ses produits ne peuvent faire l'objet d'un droit patrimonial.)

Cada quien tiene derecho a que se le respete su cuerpo.

El cuerpo humano es inviolable.

El cuerpo humano, sus elementos y sus productos no pueden ser objeto de un derecho patrimonial.

Artículo 16-2.

Le juge peut prescrire toutes mesures propres à empêcher ou faire cesser une atteinte illicite au corps humain ou des agissements illicites portant sur des éléments ou des produits de celui-ci, y compris après la mort.

El Juez puede prescribir todas las medidas necesarias para evitar o cesar un ataque ilícito hacia el cuerpo humano o actuaciones ilícitas que afecten elementos o productos del mismo.

Artículo 1240.

Tout fait quelconque de l'homme, qui cause à autrui un dommage, oblige celui par la faute duquel il est arrivé à le réparer.

Todo hecho del hombre que cause a otro un daño, obliga a éste por cuya falta se hubiese producido a reparar dicho daño. 


\title{
El daño moral como parte de la responsabilidad civil en el Derecho Internacional Privado
}

Año 11, Número 20 enero-junio 2019

Eusebio Francisco Tulio Flores Contreras

\begin{abstract}
Artículo 1241.
Chacun est responsable du dommage qu'il a causé non seulement par son fait, mais encore par sa négligence ou par son imprudence.

Cada cual será responsable del daño que cause no solamente por su actuación, sino también por su negligencia o por su imprudencia.
\end{abstract}

Artículo 1245-8.

Le demandeur doit prouver le dommage, le défaut et le lien de causalité entre le défaut et le dommage.

El demandante debe probar el daño, la falta y el nexo causal entre la falta y el daño.

Lo importante a resaltar del Código Civil Francés es el Capítulo II de su Libro Primero, titulado "Del Respeto del Cuerpo Humano" (Du Respect du Corps Humain). Es interesante como la codificación napoleónica ha instituido una primacía hacia el ser humano. No solo prohíbe ataques hacia la dignidad, integridad del ser humano como tal, sino que también establece que el hecho de su muerte no pasa por alto el respeto que le tenemos que dar al mismo.

Ahora, adminiculando las disposiciones transcritas, nos damos cuenta que el juez francés tiene al alcance todas aquellas medidas que estime pertinentes para cesar o evitar ataques hacia la integridad de la persona. Por lo que podemos decir que éste tiene una libre valoración para resolver en cuanto a la cuantificación de daño moral se trate, sin embargo, debe de estar seguro de la existencia indubitable del daño, mismo que lo hará tomando lo que establece el artículo 1245-84:

1.- El daño.

2.- La falta (el acto ilícito propiamente dicho)

3.- El Nexo de causalidad entre estos dos.

\section{Criterios judiciales.}

Monsieur $X$ Thierry y Compagnie Fiduciaire Antiboise vs. Monsieur Y Denis, 12 de Septiembre de 2007, Tribunal de Instancia de Niza. ${ }^{5}$

Este caso podemos estudiarlo a partir de un extracto de las determinaciones más relevantes sostenidas por el Tribunal de Instancia de Niza, dividiéndolas en dos apartados: determinación de procedencia de la vía y estudio del daño moral.

\section{Determinación de procedencia de la vía.}

\footnotetext{
${ }^{4}$ Artículo que me atrevo a aplicar por analogía, ya que el mismo es relativo al apartado de la Responsabilidad Extracontractual por productos defectuosos. Sin embargo, el mismo aplica un principio fundamental del derecho civil, el principio Sine Qua Non.

${ }^{5}$ https://www.legifrance.gouv.fr/affichJuriJudi.do?oldAction=rechExpJuriJudi\&idTexte=JURITEXT0000184317 70\&fastReqld=1899467801\&fastPos $=7$ (consultado el 29 de marzo de 2019)
} 
En Francia, existe una Ley, especial para la materia de libertad de expresión (Loi du 29 Julliet 1881). Ésta regula primordialmente a la prensa, por lo que su aplicación en el caso se puso en disputa, pues en la especie, el caso se trata básicamente de difamaciones realizadas entre particulares. Sin embargo, el Tribunal de Instancia de Niza, sostuvo diversos argumentos:

En effet, même si les dispositions de ce texte législatif ont été élargies à d'autres cas que les diffamations ou injures diffusées par voie de presse, le seul fait que la demande consiste en une action civile pour diffamation ou injure n'implique pas nécessairement l'application de cette loi.

En efecto, aunque las disposiciones de este texto legislativo se han ampliado a otros casos distintos de las difamaciones o injurias difundidas por la prensa, el mero hecho de que la solicitud consista en una acción civil por difamación o injuria no implica necesariamente la aplicación de esta ley.

L'article 29 de la loi du 29 juillet 1881 définit la diffamation et l'injure. Ainsi, toute allégation ou imputation d'un fait qui porte atteinte à l'honneur ou à la considération de la personne ou du corps auquel le fait est imputé est une diffamation. La publication directe ou par voie de reproduction de cette allégation ou de cette imputation est punissable, même si elle est faite sous forme dubitative ou si elle vise une personne ou un corps non expressément nommés, mais dont l'identification est rendue possible par les termes des discours, cris menaces, écrits ou imprimés, placards ou affiches incriminés. Toute expression outrageante, termes de mépris ou invective qui ne renferme l'imputation d'aucun fait est une injure.

El artículo 29 de la Ley de 29 de julio de 1881 define la difamación y la injuria. Así pues, toda alegación o imputación de un hecho que atente contra el honor o la consideración de la persona o del cuerpo al que se atribuye el hecho constituye difamación. La publicación directa o por medio de reproducción de esta alegación o de ésta imputación será punible, incluso si se hace en forma dubitativa o sí apunta una persona o un cuerpo no expresamente nombrados, pero cuya identificación es posible por los términos de los discursos, gritos, amenazas, escritos o impresiones, placares o afiches incriminatorios. Toda imputación de desprecio o invectiva, que no contenga la imputación ningún hecho, es una injuria

L'article 32 de la loi du 29 juillet 1881, qui prévoit les cas de diffamation envers des particuliers, renvoie à l'article 23 de la loi pour la définition des moyens par lesquels la diffamation est commise. Or, en vertu de l'article 23 de la loi susvisée, ces moyens sont les suivants : des discours, cris ou menaces proférés dans des lieux ou réunions publics, soit par des écrits, 


\section{El daño moral como parte de la responsabilidad civil en el Derecho Internacional Privado}

Año 11, Número 20 enero-junio 2019

Eusebio Francisco Tulio Flores Contreras

imprimés, dessins, gravures, peintures, emblèmes, images ou tout autre support de l'écrit, de la parole ou de l'image vendus ou distribués, mis en vente ou exposés dans des lieux ou réunions publics, soit par des placards ou des affiches exposés au regard du public, soit par tout moyen de communication au public par voie électronique.

El artículo 32 de la Ley de 29 de julio de 1881, que prevé los casos de difamación contra particulares, remite al artículo 23 de la ley para la definición de los medios por los que se comete la difamación. Ahora bien, en virtud del artículo 23 de la ley mencionada, estos medios son los siguiente: discursos, gritos o amenazas proferidos en lugares o reuniones públicas, ya sea por escritos, impresos, dibujos, grabados, pinturas, emblemas, imágenes o cualquier otro soporte del escrito, la palabra o la imagen vendidos o distribuidos, puestos a la venta o expuestos en lugares o reuniones públicos, ya sea mediante carteles expuestos a la vista del público, por cualquier medio de comunicación pública o por vía electrónica

...

D'ailleurs, Monsieur X... Thierry et la Compagnie Fiduciaire Antiboise ne se réfèrent dans leurs écritures, à l'article 29 de la loi de 1881 que définir la diffamation, mais leur demande de réparation du préjudice résultant de la diffamation est fondée sur les dispositions de l'article 1382 du code civil. Ils convient d'ailleurs de relever qu'ils sollicitent d'ailleurs du tribunal de qualifier les imputations contenues dans la lettre de Monsieur Y... Denis de diffamation non publique engageant sa responsabilité.

Por otra parte, el señor $X$ Thierry y la Compagnie Fiduciaire Antiboise, no se refiere en sus escritos, al artículo 29 de la ley de 1881en cuanto definir la difamación, pero que su demanda de reparación del perjuicio resultante de la difamación está basada en las disposiciones del artículo 1382 del Código Civil. Es conveniente revelar que los actores solicitaron por otra parte al Tribunal, calificar las imputaciones contenidas en la carta del señor Y Denis de difamación no publica, dando lugar a su responsabilidad.

\section{Estudio del daño moral.}

Las determinaciones que veremos en este apartado son básicamente la Litis del caso en estudio. Pasaremos desde las alegaciones hechas por la parte actora hasta la condena que determinó el Tribunal en relación al daño moral

Selon l'article 1382 du code civil, tout fait quelconque de l'homme, qui cause à autrui un dommage, oblige celui par lequel il est arrivé, à le réparer. 
Según el artículo 1382 del Código Civil, todo hecho con el que el hombre cause a otro un daño, obliga a éste a repararlo.

En l'espèce, Monsieur Y... Denis a adressé à la Compagnie Fiduciaire Antiboise et à Monsieur X... Thierry un courrier recommandé avec avis de réception, en date du 16 octobre 2005, présenté le 20 octobre 2005, dans lequel il y est indiqué:

En la especie, el señor Y Denis, envió a la Compagnie Fiduciaire Antiboise y al señor $X$ Thierry, un correo certificado con acuse de recibo de fecha 16 de octubre de 2005, presentado el 20 de octubre de 2005, en el cual se indicó que:

«Monsieur,

Il est évident que vous défendez mieux vos INTERETS que les intérêts de VOS CLIENTS ; Surtout quand la totalité de vos honoraires vous ont été réglés COMPTANT (Affaire CASINO/Y...). Vous respectez plus facilement les dates vous concernant, que les dates que vous aviez négociées et que vous n'avez pas su faire respecter à mon EXPERT-COMPTABLE et votre AMIE madame $Z$.... Le jugement pour l'affaire CASINO a été rendu, et l'on peut s'apercevoir que les seuls griefs qui m'ont été retenus et I'INCAPACITE de mes CONSEILS.

Je me réserve donc le droit de voir avec mon AVOCAT ; les suites à donner à cette affaire ; Et suite il y aura!

Pour faire suite à mon courrier par lequel je m'engageais à vous payer ; Vous trouverez donc ci-joint un chèque no4597747 à tirer sur le CREDIT AGRICOLE pour la S.A.R.L. VITAL. Je vous règle la totalité de la somme par CHEQUE, soit cinq cent quarante euros cinquante et un cents (540,51). J'attends toujours la FACTURE DES $50 \%$ QUE VOUS m'avez fortement suggéré de vous régler en ESPECES!

Je vous salue.

Monsieur Y...

PS : Copie à MAITRE A.... »

Señor,

Es evidente que usted defiende mejor sus INTERESES que los intereses de SUS CLIENTES; sobre todo cuando la totalidad de sus honorarios han sido ajustados tomando en cuenta (caso CASINO)/Y...)

Usted respeta más fácilmente las fechas que le conciernen, que la fechas que usted había negociado y que usted no ha sabido hacer respetar a mi EXPERTA-CONTABLE y su AMIGA la señora Z... 


\section{El daño moral como parte de la responsabilidad civil en el Derecho Internacional Privado}

Año 11, Número 20 enero-junio 2019

Eusebio Francisco Tulio Flores Contreras

La sentencia en el caso CASINO ha sido dictada y solo nos podemos dar cuenta de las únicos cargos que me han sido imputados es la INCAPACIDAD de mis CONSEJOS.

Me reservo entonces el derecho junto con mi ABOGADO, el seguimiento se le deba dar a este asunto; ;Y de hecho habrá!.

Por dar seguimiento a mi correo en el que me comprometía a pagarle; usted encontrará adjunto un cheque no. 4597747 que debe ser transferido a CREDIT AGRICOLE para la S.A.R.L VITAL.

Le pago la totalidad de la suma por CHEQUE, es decir, quinientos cuarenta euros y un céntimos $(540,51)$.

¡Sigo esperando la FACTURA del $50 \%$ que usted me ha sugerido firmemente que les pague con ESPECIES!

Lo saludo..

Señor $Y$

PD: copia para MAITRE A..

Monsieur X... Thierry et la Compagnie Fiduciaire Antiboise font valoir que les imputations contenues dans cette lettre constituent une diffamation non publique à leur encontre. Monsieur Y... Denis le conteste, faisant valoir que la lettre qu'il a ainsi adressée aux demandeurs est un simple courrier de mécontentement.

El Señor X Thierry y la Compagnie Fiduciaire Antiboise hacen valer que las imputaciones contenidas en dicha carta constituyen una difamación no publica a su encuentro. El Señor Y Denis, les sostiene que la carta que también él envió a los demandantes es un simple correo de descontento.

Toute expression qui contient l'imputation d'un fait précis et déterminé, de nature à porter à l'honneur ou à la considération de la personne visée, constitue une diffamation, même si elle est présentée sous une forme déguisée ou dubitative ou par voie d'insinuation.

Toda expresión que contenga la imputación de un hecho preciso y determinado, respecto al honor o la consideración personal, constituye una difamación, incluso si esta es presentada de manera disfrazada o dudosa o de modo de insinuación.

S'il est vrai que cette lettre apparaît comme une lettre de mécontentement, ses termes contiennent néanmoins l'imputation de faits de nature à porter atteinte à l'honneur et à la considération de Monsieur $X$... Thierry, avocat. En effet, le premier paragraphe fait état de ce que cet avocat néglige les intérêts de ses clients au profit de ses intérêts personnels. En outre, le dernier paragraphe suggère que le destinataire du courrier perçoit des honoraires de façon illégale.

Bien es cierto que dicha carta aparenta ser una carta de descontento, sin embargo sus términos contienen la imputación de hechos que atentan contra el honor y la consideración del Señor $X$ Thierry, abogado. En 
efecto, el primer párrafo hace referencia que dicho abogado denigra los intereses de sus clientes en preferencia de sus intereses personales. Por otro lado, el último párrafo, sugiere que el destinatario del correo perciba sus honorarios de manera ilegal.

Le préjudice qui en résulte pour le demandeur est simplement moral, d'autant plus qu'une copie courrier a été adressée à une tierce personne (Me B...).

El perjuicio que resulta por el demandante es simplemente moral, tanto así que una copia del correo fue enviada a una tercera persona (Me B..) ...

Monsieur Y... Denis sera donc condamné à payer à Monsieur $X$... Thierry la somme de un euro (1) en réparation du préjudice moral résultant des imputations de nature à porter atteinte à son honneur et à sa considération, contenues dans la lettre recommandée avec avis de réception en date du 16 octobre 2005.

El Señor Y Denis es entonces condenado a pagar al Señor $X$ Thierry la summa de un euro (1) en reparación del daño moral resultante de las imputaciones encaminadas a atentar en contra de su honor $y$ consideración, contenidas dentro de la carta con acuse de recibo de fecha de 16 de octubre de 2005.

PAR CES MOTIFS, POR ESTOS MOTIVOS

Le tribunal, statuant par jugement contradictoire et en dernier ressort, prononcé par mise à la disposition du public au greffe, El tribunal actuando por un juicio contradictorio y en última instancia, pronunciado gracias a la disposición del público al registro.

Déclare Monsieur Y... Denis responsable du préjudice causé à Monsieur $X$... Thierry par les imputations de nature à porter atteinte à son honneur et à sa considération, contenues dans la lettre recommandée avec avis de réception en date du 16 octobre 2005 ;

Declara (el tribunal) al Señor Y Denis responsable del daño moral causado al Señor $X$ Thierry por las imputaciones en contra de su honor $y$ consideración contenidas dentro de la carta con acuse de recibo de fecha de 16 de octubre de 2005;

Condamne, en conséquence, Monsieur Y... Denis à payer à Monsieur X... Thierry la somme de un euro (1) à titre de dommages et intérêts, en réparation de son préjudice moral;

Condena (el tribunal), en consecuencia, al Señor Y Denis a pagar al Señor $X$ Thierry la suma de un euro (1) a título de daños y perjuicios, en reparación de su daño moral. 


\section{DERECHO ESPAÑOL}

Es importante también dar un vistazo a la legislación interna de otros países. Por ello en el caso del Derecho Español nos centraremos más en el estudio de la Ley de Protección Civil del Derecho al Honor, a la intimidad personal y familiar y a la propia imagen, especial en materia de daños morales, más que en el Código Civil de este país.

Procederemos a resaltar los artículos de mayor relevancia hacia nuestro tema de estudio

Ley de Protección Civil del Derecho al Honor, a la intimidad personal y familiar y a la propia imagen. ${ }^{6}$

La tutela judicial comprenderá la adopción de todas las medidas necesarias para poner fin a la intromisión ilegítima de que se trate $y$, en particular, las necesarias para:

a) El restablecimiento del perjudicado en el pleno disfrute de sus derechos, con la declaración de la intromisión sufrida, el cese inmediato de la misma y la reposición del estado anterior. En caso de intromisión en el derecho al honor, el restablecimiento del derecho violado incluirá, sin perjuicio del derecho de réplica por el procedimiento legalmente previsto, la publicación total o parcial de la sentencia condenatoria a costa del condenado con al menos la misma difusión pública que tuvo la intromisión sufrida.

b) Prevenir intromisiones inminentes o ulteriores.

c) La indemnización de los daños y perjuicios causados.

d) La apropiación por el perjudicado del lucro obtenido con la intromisión ilegítima en sus derechos

La existencia de perjuicio se presumirá siempre que se acredite la intromisión ilegítima. La indemnización se extenderá al daño moral, que se valorará atendiendo a las circunstancias del caso y a la gravedad de la lesión efectivamente producida, para lo que se tendrá en cuenta, en su caso, la difusión o audiencia del medio a través del que se haya producido.

El importe de la indemnización por el daño moral, en el caso de los tres primeros apartados del artículo cuarto, corresponderá a las personas a que se refiere su apartado dos y, en su defecto, a sus causahabientes, en la proporción en que la sentencia estime que han sido afectados. En los casos del artículo sexto, la indemnización se entenderá comprendida en la herencia del perjudicado

${ }^{6}$ https://www.boe.es/buscar/pdf/1982/BOE-A-1982-11196-consolidado.pdf (recuperado el 17 de marzo de 2019) 


\section{Criterios Judiciales.}

En la iuris praxis de España, los tribunales han creado una tendencia de conceder a la víctima una indemnización global por los daños materiales y morales que se traten en el caso en concreto, pasando por alto el hecho de realizar un estudio pormenorizado de las circunstancias que atañen a cada tipo de daño. ${ }^{7}$

Si bien no cabe duda que, un hecho dañoso puede ocasionar una pluralidad de afectaciones patrimoniales y/o morales, a la hora de resolver, el órgano jurisdiccional debería de enumerar diferenciadamente cada una de las partidas del daño.

Lo dicho en líneas precedentes es probable que se deba a la propia conducta de los actores, que en sus pretensiones realizan una petición global (en cuanto a la indemnización del daño) sin ulteriores distingos, aunque a veces es la pereza del Juzgador o las complicaciones del caso lo que conduce a una indemnización global, pese a que el actor imputó en su demanda una cantidad a cada concepto de daño.

A continuación, observemos algunas determinaciones judiciales de España para pasar a su debido análisis.

Sentencia No. 365 de 30 de Diciembre de 2002 (Audiencia Provincial en Zamora, España)

"Sin lugar a dudas no es tarea fácil llevar a cabo una cuantificación del daño moral, declarando la Jurisprudencia (STS 29-1-93) que su determinación corresponde de modo discrecional por el Juez en atención a las necesidades y circunstancias del caso, lo que se aduce en la Sentencia de 9-12- 94, al señalar que es indudable que el daño moral no puede descansar en una prueba objetiva, debiendo apreciarse en cada caso, Según las circunstancias concurrentes. Doctrina jurisprudencial que señala el supuesto de daños morales producidos en supuesto incardinados en el art. 14.4 ${ }^{\circ}$ L.P.I (Sent. 8.11-95, 20-2-98, 22-4-98), refrendada por la más reciente de 28-1-00, llevan a la conclusión de que habida cuenta que los daños morales no tienen apreciación tangible y su valoración no puede obtenerse en una prueba objetiva, a cuya selectiva o imprecisión imprime una exigencia judicial respecto de su existencia y traslación económica o patrimonial, exige utilización de un prudente criterio, que debe ser respetado y no alterado siempre que la cuantificación sea ponderada y prudente.

En la presente litis, y contrariamente a las consideraciones que efectúa la apelante de no haberse producido ningún daños moral, de las pruebas practicadas y atendiendo a los criterios del propio art 140, ha resultado probada, la infracción de los derechos de autor, como resulta de los expuesto ut supra, que gracias, entre otros, a los trabajos encomendados

\footnotetext{
${ }_{7}^{7}$ LÓPEZ SÁNCHEZ, C., "La indemnización del daño moral derivado de la infracción de derechos de propiedad intelectual e industrial", en Problemática actual de la tutela civil ante la vulneración de la propiedad industrial e intelectual, coord. J.A. Moreno Martínez, Dykinson, Madrid, 2017, pág. 289
} 
El daño moral como parte de la responsabilidad civil en el Derecho Internacional Privado

Año 11, Número 20 enero-junio 2019

Eusebio Francisco Tulio Flores Contreras

a los actores, DIRECCION001 fue beneficiaria de las ayudas correspondientes con cargo a los fondos estructurales de la Unión Europea, está igualmente acreditado la distribución del libro y folletos en ferias (cerca de 1500ejemplares), sin que para nada aparezca quien es el autor de los mismos, (ver periódicos y cinta de video aportada) la inclusión en páginas web, de alguno de los folletos junto con la distribución gratuita al público en general, sin hacerlo sabedor de la autoría, sin lugar a dudas supone una vulneración del daño moral y su cuantificación en 150.000 ptas. se considera prudente y ponderada en relación con el precio del encargo y ganancias que hubiera podido obtener la actora de distribuir y editar el libro y folletos, por lo que debe perecer, también este motivo." 8

"La valoración del daño moral en términos objetivos resulta concretamente difícil, por no decir imposible, cualquier indemnización que se establezca o se condene por este concepto es en cierto modo arbitraria. El origen tan ambiguo del daño moral ha permitido a los tribunales emplearlo de forma extensiva. El aspecto resarcitorio del daño moral atiende a elementos concretos: el tipo de obra, su característica más o menos entrañable según sea el autor, sus herederos o cesionarios legítimos y con facultad exclusiva vigente; las condiciones del lesionado, como la edad, dedicación, situación económica; la extensión o repercusión del hecho violador (es más insoportable la difusión en los carteles publicitarios, o por televisión, que en vidrieras o afiches aislados); la calidad de la obra plagiada y sus efectos en otros bienes personalísimos, como el honor también herido, la imagen personal puesta en la calle, o la difusión de la intimidad de un autor". ${ }^{9}$

\section{DERECHO ARGENTINO}

Código Civil para la República Argentina.

Art.522.

En los casos de indemnización por responsabilidad contractual el juez podrá condenar al responsable a la reparación del agravio moral que hubiere causado, de acuerdo con la índole del hecho generador de la responsabilidad y circunstancias del caso.

Art.1072.-

\footnotetext{
${ }^{8}$ http://www.poderjudicial.es/search/contenidos.action?action=contentpdf\&databasematch=AN\&reference $=2400738 \&$ statsQueryld=104688822\&calledfrom=searchresults\&links=da\%C3\%B10\%20moral\&optimize $=20$ 040515\&publicinterface=true (recuperado el 27 de Marzo 2019)

${ }^{9}$ Cifuentes, S.: «Los daños en materia de propiedad intelectual», disponible en www.cadra.org.ar/ upload/Cifuentes_Danos_Propiedad_Intelectual.pdf, consultado el 20-03-2017, pp. 6-7.
} 
El acto ilícito ejecutado a sabiendas y con intención de dañar la persona o los derechos de otro, se llama en este Código "delito".

Art.1074.-

Toda persona que por cualquier omisión hubiese ocasionado un perjuicio a otro, será responsable solamente cuando una disposición de la ley le impusiere la obligación de cumplir el hecho omitido.

Art.1078.-

La obligación de resarcir el daño causado por los actos ilícitos comprende, además de la indemnización de pérdidas e intereses, la reparación del agravio moral ocasionado a la víctima.

La acción por indemnización del daño moral sólo competerá al damnificado directo; si del hecho hubiere resultado la muerte de la víctima, únicamente tendrán acción los herederos forzosos.

Art.1099.-

Si se tratare de delitos que no hubiesen causado sino agravio moral, como las injurias o la difamación, la acción civil no pasa a los herederos y sucesores universales, sino cuando hubiese sido entablada por el difunto.

Es interesante ver la manera con la cual Argentina regula el daño moral. En un principio pareciere que éste se encuentra condicionado o sujeto a una relación contractual. Sin embargo más adelante nos damos cuenta que su existencia autónoma si se encuentra justificada, dándole la denominación de "delito"10.

El Código en cita establece dos elementos cruciales que debe tomar en cuenta un Juzgador a la hora de determinar la procedencia la reparación del agravio moral en un caso en concreto:

1.- La índole del hecho generador de la responsabilidad.

2.- Demás circunstancias del caso.

\section{Criterios de la Corte Suprema de la Nación Argentina}

La Corte Suprema de la Nación Argentina no ha sido ajena en cuanto a la indemnización del daño moral, e incluso ha establecido criterios de los cuales solo tomaremos algunos para su análisis.

Fallo 329:4111 de 26 de septiembre de 2006, relativo a, Gabriel Luis Murman vs. IBM Argentina S.A. y otra.

"Por no ser el daño moral susceptible de apreciación económica, sólo deberá buscarse una relativa satisfacción del agraviado,

\footnotetext{
${ }^{10}$ Entendiendo en este concepto al delito como aquel incumplimiento a una obligación preexistente, generador de un perjuicio por otra persona y cometido con la intención de dañarla. (Julien Bonnecase, Tratado Elemental de Derecho Civil)
} 
El daño moral como parte de la responsabilidad civil en el Derecho Internacional Privado

Año 11, Número 20 enero-junio $2019 \quad$ Eusebio Francisco Tulio Flores Contreras

proporcionándole una suma de dinero que no deje indemne el agravio, pero sin que ello represente un lucro que pueda desvirtuar la finalidad de la reparación pretendida."11

Fallo 330:2748 de 12 de junio de 2007, relativo a Raúl Alberto Serradilla vs. Provincia de Mendoza y otros.

"...Procede el resarcimiento del daño moral sufrido, detrimento que

por su índole espiritual debe tenérselo por configurado, en las circunstancias del caso, por la sola realización del hecho dañoso de que se trata y su particular naturaleza, así como la índole de los derechos comprometidos. A fin de la fijación del quantum debe tenerse en cuenta el carácter resarcitorio de este rubro, la índole del hecho generador de la responsabilidad y la entidad del sufrimiento causado, que no tienen necesariamente que guardar relación con el daño material, pues no se trata de un daño accesorio a éste (Fallos: 308:698; 318:1598; 321:1117, entre otros), así como otras circunstancias configuradas por los antecedentes como cuenta correntista bancario de Serradilla y la dependencia de ese modo de pago en cuanto a la cancelación de sus gastos de subsistencia. Dejando de lado el sufrimiento padecido por el fallecimiento de la esposa del actor, circunstancia que no es atribuible con ningún alcance a las demandadas, lo cierto es que la falta de servicio examinada ut supra fue susceptible de provocar molestias, padecimientos aflicciones espirituales, que justifican la admisión del rubro reclamado."12

Fallo 334:376 de 12 de abril de 2011, relativo a Silvia Ofelia Baeza vs. Provincia de Buenos Aires y otros.

Que en lo concerniente a la fijación del daño moral, debe tenerse en cuenta el carácter resarcitorio de este rubro, la índole del hecho generador de la responsabilidad, la entidad del sufrimiento causado, que no tiene necesariamente que guardar relación con el daño material, pues no se trata de un daño accesorio a éste (Fallos: 321:1117; 323:3614 y 325:1156, entre otros). El dolor humano es apreciable y la tarea del juez es realizar la justicia humana; no se trata de una especulación ilícita con los sentimientos sino de darle a la víctima la posibilidad de procurarse satisfacciones equivalentes a lo que ha perdido. Aun cuando el dinero sea un factor muy inadecuado de reparación, puede procurar algunas satisfacciones de orden moral, susceptibles, en cierto grado, de reemplazar en el patrimonio moral el valor que del mismo ha

11

https://sjconsulta.csin.gov.ar/sjconsulta/documentos/verDocumentoByldLinksJSP.html?idDocumento=6089 $\underline{501 \& \text { cache }=1553564906651}$ (recuperado el 25 de marzo de 2019)

${ }^{12}$ https://sjconsulta.csjn.gov.ar/sjconsulta/documentos/verDocumentoByldLinksJSP.html?idDocumento=628 9961\&cache=1553564292518 (Recuperado el 25 de marzo de 2019) 
desaparecido. Se trata de compensar, en la medida posible, un daño consumado. En este orden de ideas, el dinero es un medio de obtener satisfacción, goces y distracciones para restablecer el equilibrio en los bienes extrapatrimoniales. ${ }^{13}$

La evaluación del perjuicio moral es tarea delicada, pues no se puede pretender dar un equivalente y reponer las cosas a su estado anterior, como en principio debe hacerse de acuerdo al art. 1083 del Código Civil. El dinero no cumple una función valorativa exacta, el dolor no puede medirse o tasarse, sino que se trata solamente de daralgunos medios de satisfacción, lo cual no es igual a la equivalencia. Empero, la dificultad en calcular los dolores no impide apreciarlos en su intensidad y grado por lo que cabe sostener que es posible justipreciar la satisfacción que procede para resarcir dentro de lo humanamente posible, las angustias, inquietudes, miedos, padecimientos y tristeza propios de la situación vivida. ${ }^{14}$

\section{Fallo 340:1038 de 10 de Agosto de 2017, relativo a Stella Maris Ontiveros vs. Prevención ART S.A. y otros.}

...esta Corte ha expresado, en diversos pronunciamientos vinculados con infortunios resueltos en el contexto indemnizatorio del código civil anterior, que en lo concerniente a la fijación del daño moral, debe tenerse en cuenta el carácter resarcitorio de este rubro, la índole del hecho generador de la responsabilidad, la entidad del sufrimiento causado, que no tiene necesariamente que guardar relación con eldaño material, pues no se trata de un daño accesorio a este (Fallos: $321: 111$ 7; 323: 3614 ; 325: 1156 Y 334: 376, entre otros), y que "e1 dolor humano es apreciable y la tarea del juez es realizar la justicia humana; no se trata de una especulación ilícita con los sentimientos sino de darle a la víctima la posibilidad de procurarse satisfacciones equivalentes a lo que ha perdido. Aun cuando el dinero sea un factor muy inadecuado de reparación, puede procurar algunas satisfacciones de orden moral, susceptibles, en cierto grado, de reemplazar en el patrimonio moral el valor que del mismo ha desaparecido" (Fallos: 334:376). ${ }^{15}$

Por ello, en la evaluación del perjuicio moral, "la dificultad en calcular los dolores no impide apreciarlos en su intensidad y grado por lo que cabe sostener que es posible justipreciar la satisfacción que procede para resarcir dentro de lo humanamente posible, las angustias,

\footnotetext{
${ }^{13}$ https://sjconsulta.csjn.gov.ar/sjconsulta/documentos/verDocumentoByldLinksJSP.html?idDocumento=442 91\&cache=1553649986358 (recuperado el 26 de marzo de 2019)

14 Ídem

${ }^{15}$ https://sjconsulta.csjn.gov.ar/sjconsulta/documentos/verDocumentoByldLinksJSP.html?idDocumento=739 $1642 \&$ cache $=1553649462151$ (recuperado el 26 de marzo de 2019)
} 
El daño moral como parte de la responsabilidad civil en el Derecho Internacional Privado

Año 11, Número 20 enero-junio 2019

Eusebio Francisco Tulio Flores Contreras

inquietudes, miedos, padecimientos y tristeza propios de la situación

vivida" (doctrina de Fallos: 334: 376) ${ }^{16}$

\title{
DERECHO CUBANO.
}

\section{Código Civil Cubano.}

\author{
ARTÍCULO 82. \\ El que causa ilícitamente daño o perjuicio a otro está obligado a \\ resarcirlo. \\ ARTÍCULO 83. \\ El resarcimiento de la responsabilidad civil comprende: \\ ... \\ ch) la reparación del daño moral. \\ ARTÍCULO 88. \\ La reparación del daño moral comprende la satisfacción al ofendido \\ mediante la retractación pública del ofensor.
}

Es curioso ver la manera con la cual Cuba regula la reparación del daño moral. En un principio nos divide diversas clasificaciones de resarcimiento de la responsabilidad civil, siendo una de esta el daño moral. Lo que hay que resaltar aquí son los factores de indemnización o de resarcimiento que establece. Por lo que a simple vista nos percatamos de uno solo, la retracción pública del ofensor.

No cabe duda que cada norma jurídica está interrelacionada con el contexto del país en el que se encuentra. Es por ello que, concibiendo a Cuba como un país con una cultura y sistema político distinto al de nosotros, podamos entender el origen de este resarcimiento moral.

\section{Criterios Judiciales.}

Quizás en nuestro tema de estudio, Cuba no tenga un entorno legislativo tan marcado como otros países, sin embargo esto no ha sido una limitante, ya que sus Tribunales se han encargado de establecer diversos criterios que nos permiten conocer un panorama más amplio de nuestro tema. A continuación veremos algunos de ellos.

SENTENCIA № 697 DE 9 DE NOVIEMBRE DEL 2002 DEL TRIBUNAL SUPREMO POPULAR DE CUBA. SALA DE LO CIVIL Y DE LO ADMINISTRATIVO, (PRIMER CONSIDERANDO. PONENTE CARRASCO CASI).

"(...) se debe partir del concepto de lo que constituye el daño moral, que no es otra cosa que la lesión de los bienes o derechos que pertenecen al ámbito personal del sujeto de derecho y que repercute de alguna manera 
en sus intereses de índole afectiva y emocional, así como que para que este daño sea estimado con relevancia jurídica, debe producir un perjuicio, una pérdida o menoscabo y también debe incidir sobre un bien jurídico de la persona y ser susceptible de resarcimiento en concepto de responsabilidad civil (...)".

Como vemos esta Sentencia nos define qué es lo que debemos de entender por daño moral en derecho cubano, y que además esta es susceptible de resarcimiento por medio de la institución de la Responsabilidad Civil.

SENTENCIA № 110 DE 2 DE NOVIEMBRE DE 1999, DICTADA POR LA SALA SEGUNDA DE LO CIVIL Y DE LO ADMINISTRATIVO DEL TRIBUNAL PROVINCIAL DE CIUDAD DE LA HABANA (34 CONSIDERANDO. PONENTE DÍAZ TENREIRO):

" (...) el bien sobre el cual se basa la reclamación es la vida en unos casos y la integridad física en otros, que dada su naturaleza son invaluables y de imposible restitución; y ante la problemática de su cuantificación a los efectos del resarcimiento que se interesa, es doctrina también mayoritaria que tanto el daño a la vida como a la integridad física de la persona debe ser cuantificado pecuniariamente, y que la reparación del daño por parte de su responsable se logra a través de una compensación de este orden que, como sostienen varias legislaciones afines a nuestro sistema jurídico, resulta de libre apreciación por el juzgador; $y$ es precisamente a este principio al que la Sala se afilia, amparada en la doctrina legal que a manera de heterointegración del Derecho se utiliza, por la razón de que nuestra fuente dominante, la Constitución y demás leyes que de ésta se derivan, al respecto no se pronuncian, todo lo que obliga al órgano jurisdiccional que resuelve, teniendo en cuenta todas las circunstancias y elementos de juicio que concurren en el proceso, como son los derechos lesionados, el grado de responsabilidad del demandado, la situación económica de éste y de los reclamantes, a fijarla en los términos interesados (...) todo ello para procurar que en lo sucesivo el demandado se abstenga de realizar actos ilícitos como los expresados (...)".

"(...)en lo que se refiere a la indemnización del daño moral, el Código Civil vigente, tal y como tantas veces se ha mencionado, lo ciñe exclusivamente a condenar al demandado a ofrecer una satisfacción a los ofendidos mediante su retractación pública (...)".

"Ninguna duda debe aportar la carencia de valoración económica que, en sí mismo, padecen estos derechos de la personalidad, ni su carácter de inherencia a la persona, pues, para que un daño sea estimado con 
El daño moral como parte de la responsabilidad civil en el Derecho Internacional Privado

Año 11, Número 20 enero-junio 2019

Eusebio Francisco Tulio Flores Contreras

relevancia jurídica, debe producir un perjuicio, una pérdida $o$ menoscabo, debe incidir sobre algún bien jurídico de la persona, y ser susceptible de resarcimiento, que del latín resarcire significa la acción o efecto de dar o recibir una indemnización o reparación por el perjuicio o agravio que se hubiere causado, de ahí que se le estime como una sanción de orden civir".

Por un lado, esta Sentencia nos sostiene que resulta difícil realizar una indemnización por un daño moral, tomando como base que esta tiene como bien tutelado a la vida misma. Sin embargo, la legislación cubana, ha establecido un sistema de libre valoración para el resarcimiento de dicho daño. Lo que lleva a que se establezcan tres criterios básicos para resolver:

1.- Los derechos lesionados.

2.- El grado de responsabilidad del demandado.

3.- La situación económica del demandado como de los reclamantes.

De igual manera, esta Sentencia reitera la falta del factor económico en la indemnización del daño moral, esto debido a que para que un daño sea susceptible a una indemnización de esta índole, debe generar de forma indubitable una perdida, perjuicio o menoscabo de algún bien jurídico de la persona misma, de ahí que solo se trate de una sanción civil.

Dicha determinación pareciere ser un tanto contradictoria, pues en un principio la Sentencia en cita nos sostiene que la afectación hacia la integridad física de una persona debe partir como base la vida misma, y al hacer el análisis hecho en líneas precedentes, nos da entender que la afectación moral carece un bien jurídico, por ende la reiteración de carencia económica con indemnización.

\section{DERECHO CANADIENSE (QUEBEC)}

\section{Código Civil de Quebec}

Artículo 1457.

(Toute personne a le devoir de respecter les règles de conduite qui, suivant les circonstances, les usages ou la loi, s'imposent à elle, de manière à ne pas causer de préjudice à autrui.

Elle est, lorsqu'elle est douée de raison et qu'elle manque à ce devoir, responsable du préjudice qu'elle cause par cette faute à autrui et tenue de réparer ce préjudice, qu'il soit corporel, moral ou matériel.

Elle est aussi tenue, en certains cas, de réparer le préjudice causé à autrui par le fait ou la faute d'une autre personne ou par le fait des biens qu'elle a sous sa garde.)

Toda persona tiene el deber de respetar las reglas de conducta que, seguidas de las circunstancias, los usos o la ley, se le impongan a ésta, de manera que no cause una lesión a otro. 
Ésta es, cuando es indubitable que falta a dicho deber, responsable de la lesión que ésta causa por dicha falta a otro y obligada a reparar la lesión, sea corporal, moral o material.

También es responsable, en ciertos casos, de reparar la lesión causada a otro por el hecho o la falta de otra persona o de bienes que se encuentren a su cargo.

En el Derecho de Quebec, como lo observamos, el daño moral se establece de una forma simple. Basta con entender que la persona se debe de regir bajo las normas de conducta que imponga la sociedad, y que, como consecuencia al infringir dicha norma, la persona será responsable de los daños ocasionados, mismos que pueden ser corporales, morales o materiales

\section{Criterios Judiciales.}

En este apartado tomaremos algunos argumentos establecidos dentro del "Judgement" Québec (Curateur public) c. Syndicat national des employés de l'hôpital St-Ferdinand ${ }^{17}$, emitido por la Corte Suprema de Canadá:

Le droit civil québécois appuie la conception voulant que le droit à la compensation du préjudice moral ne soit pas conditionnel à la capacité de la victime de profiter ou de bénéficier de la compensation monétaire. Cette caractérisation objective du préjudice moral s'accorde mieux avec les principes fondamentaux de la responsabilité civile que la conception subjective. Au Québec, la principale fonction du régime de responsabilité civile est de compenser le préjudice. Cet objectif commande l'indemnisation de la perte subie en raison du comportement fautif, peu importe que la victime soit en mesure de profiter des joies substituées. Pour caractériser la nature du préjudice moral pour fins d'indemnisation, la conception purement subjective n'a donc pas sa place en droit civil puisque les dommages sont recouvrables, non pas parce que la victime pourra en bénéficier, mais plutôt en raison même de l'existence d'un préjudice moral. L'état ou la capacité de perception de la victime ne sont pas pertinents quant au droit à la compensation du préjudice moral.

El derecho civil de Quebec apoya la concepción de que el derecho a la compensación del daño moral no debe ser condicionado a la capacidad de la víctima de aprovechar o beneficiar de una compensación monetaria. Esta caracterización objetiva del daño moral se entiende

\footnotetext{
${ }^{17} \mathrm{https} / / /$ scc-csc.lexum.com/scc-csc/scc$\mathrm{csc} / \mathrm{fr} /$ item/1423/index.do?q=pr\%C3\%A9judice+moral+dommage+moral (recuperado el 18 de febrero de 2019)
} 


\section{El daño moral como parte de la responsabilidad civil en el Derecho Internacional Privado}

Año 11, Número 20 enero-junio 2019

Eusebio Francisco Tulio Flores Contreras

mejor con los principios fundamentales de la Responsabilidad Civil que con una concepción subjetiva. En Quebec, la principal función del régimen de la Responsabilidad Civil es de compensa el daño. Ese objetivo rige la indemnización de la pérdida sufrida en razón del comportamiento culposo, poco importa que la víctima éste en capacidad de gozar de placeres sustituidos. Por caracterizar la naturaleza del daño moral a efectos de indemnización, la concepción puramente subjetiva no tiene su lugar en el derecho civil, esto debido a que los daños son recuperables, y no porque la víctima pueda gozar de ellos, sino más bien, en la razón misma de la existencia de un daño moral. El estado o la capacidad de percepción de la víctima no son adecuados en cuanto al derecho a la compensación del daño moral.

Le préjudice moral a été défini comme comprenant la perte de jouissance de la vie, le préjudice esthétique, les douleurs et souffrances physiques et psychologiques, les inconvénients, de même que le préjudice d'agrément et le préjudice sexuel. Or, pourquoi indemniser la victime d'un préjudice qui est, à strictement parler, irréparable? II est toutefois indéniable que le préjudice moral constitue un préjudice réel.

El daño moral ha sido definido incluyendo la pérdida del goce de la vida, el daño estético, los dolores y sufrimientos físicos y psicológicos, inconvenientes, daño a la aprobación y daños sexuales. ¿Y porque indemnizar a la víctima de un daño que es, estrictamente hablando, irreparable? Es innegable que el daño moral constituye un daño real.

Au niveau du calcul de l'indemnité, on peut aborder le préjudice moral de trois façons différentes, lesquelles, comme nous le verrons, se complètent beaucoup plus qu'elles ne s'opposent. II s'agit des approches conceptuelle, personnelle et fonctionnelle, que nous examinerons brièvement tour à tour.

Al nivel del cálculo de la indemnización, podemos abordar el daño moral de tres maneras diferentes, las cuales, como las veremos, se complementan entre sí más que distanciarse. Se trata de los enfoques : conceptual, personal y funcional.

L'approche dite conceptuelle considère les composantes de l'être humain comme possédant une valeur purement objective, traduite par un montant monétaire spécifique. Cette méthode, d'une grande simplicité, a l'inconvénient majeur de ne pas tenir compte de la situation particulière 
de la victime. Elle a, en effet, été critiquée comme étant une conception «primitive»

El enfoque conceptual considera los componentes del ser humano como poseyendo de un valor puramente objetivo, traducido en un monto económico especifico. Este método de gran simplicidad, tiene el inconveniente de no tomar en cuenta la situación particular de la víctima. Por esas circunstancias, ha sido criticada como una concepción 'primitiva'.

Deuxièmement, à l'antipode de l'approche conceptuelle, la méthode personnelle de calcul des dommages moraux permet d'évaluer la compensation correspondant spécifiquement à la perte subie par la victime. Cette approche "n'accorde aucune valeur objective aux organes du corps humain mais s'attache plutôt à évaluer, d'un point de vue subjectif, la douleur et les inconvénients découlant des blessures subies par la victime».

En segundo lugar, cerca del enfoque conceptual, tenemos el método personal de cálculo de daños morales. Nos permite evaluar la compensación encaminada específicamente hacia la pérdida sufrida por la víctima. Este enfoque no establece ningún valor objetivo a órganos del cuerpo humano, pero se enlaza más que nada a evaluar, desde un punto de vista subjetivo, el dolor y los inconvenientes derivados de lesiones sufridas por la víctima.

L'approche personnelle, qui refuse donc de standardiser le calcul du préjudice moral, n'est pas favorisée dans la jurisprudence québécoise lorsque le préjudice moral est grave et commande le versement du montant maximal de dommages moraux. Elle semble néanmoins être pertinente dans les cas de préjudices de moyenne et faible importance. II y a, alors, évaluation séparée des diverses composantes du préjudice moral, indice de l'application de l'approche personnelle.

El enfoque personal, que rechaza el estandarizar el cálculo del daño moral, no es aceptado en la jurisprudencia quebequense. Esto debido a que el daño moral es grave y comanda el pago del monto máximo del daño moral. No obstante parece ser pertinente en los casos de mediana y baja importancia.

Existe entonces una evaluación separada de diversos componentes del daño moral, indicia la aplicación del enfoque personal. 


\section{El daño moral como parte de la responsabilidad civil en el Derecho Internacional Privado}

Año 11, Número 20 enero-junio 2019

Eusebio Francisco Tulio Flores Contreras

Enfin, la troisième méthode de calcul des dommages moraux, réfère à l'approche fonctionnelle..., cette approche cherche à calculer les «moyens matériels de rendre la vie de la victime plus supportable [. . .] puisqu'il faut accepter le fait que cette perte [subie] ne peut en aucune façon être réparée directement»

Por último, el tercer método de cálculo del daño moral, se trata del enfoque funcional. Este busca calcular los medios materiales de rendir la vida de la víctima más soportable, pues hay que aceptar el hecho de que dicha pérdida sufrida, no se puede de ninguna manera, ser reparada directamente.

\section{SISTEMA DE COMMON LAW}

Al ser el Common Law, un sistema jurídico muy distinto al que se maneja en los países que vimos a lo largo de este apartado, cabe hacer una hablar primordialmente de dos de sus grandes exponentes, el Derecho Norteamericano y el Derecho Inglés.

Dicho lo anterior, daremos un vistazo a la regulación que existe en éstos últimos en tratándose a daño moral.

\section{Breve contexto histórico y legal.}

Si bien en todas las demás comparativas que hicimos con antelación, abordábamos más que nada la codificación y los criterios judiciales que existían alrededor de nuestro tema de estudio, debemos de entender que el Sistema Anglosajón se basa esencialmente en la jurisprudencia y costumbre por lo que tenemos que hablar forzadamente de una institución que consideremos análoga al Daño Moral que hemos estado estudiando, esta es el Non Pecuniary Loss.

El estudio del daño no económico (Non Pecuniary Loss) en el Common Law inglés conduce a dos orígenes. El primero es derivado de la acción Assault, en la cual el demandado debe de indemnizar a la víctima por haber realizado una amenaza de violencia física. Ésta fue reconocida por primera vez en 1348 en el caso de I de $S$ et $U x$ vs. $W$ de $S$, en el que un esposo demandó por la aprensión que sufrió su esposa producto de un ataque fallido con un hacha. Máxime que la esposa no sufrió una herida física, el esposo recibió una compensación. ${ }^{18}$

El segundo origen es la "ley de difamación". En su comienzo, los pleitos surgidos por conductas y actos difamatorios eran resueltos por las cortes eclesiásticas. El hecho de difamar a otra persona era considerado un pecado y el responsable sólo debía realizar penitencia. Cualquier intento de la víctima por

\footnotetext{
${ }^{18}$ Rodríguez, Zamudio, R. El Daño no económico en el Derecho Estadounidense, Revista Facultad de Derecho y Ciencias Políticas, Vol. 44, No. 121, Julio-Diciembre, 2014. Medellín, Colombia. Págs. 615-616
} 
obtener una compensación pecuniaria era rechazado con una orden de prohibición (writ of prohibition) $)^{19}$

En 1274 el scandalum magnatum ${ }^{20}$ se tomó como base principal, dando como resultado una serie de leyes que regulaban y penaban la difamación, es decir, se sacaron estos casos de la jurisdicción de las cortes eclesiásticas para ponerlos en la tutela de las cortes del rey. La mayoría de estas leyes, que tenían un origen político y pertenecían a la rama del derecho penal, no fueron muy utilizadas hasta el reinado de Elizabeth. Para que la acción del demandante prosperara era necesario que la difamación estuviera acompañada de una agresión o, por lo menos, la amenaza de una agresión. ${ }^{21}$

Era muy importante lo que se dijera en juicio, y los tribunales no querían que en base argumentos poco solidos se dictaran sentencias condenatorias de daño moral, con la aparición de la imprenta pudo tener más efecto de probanza.

Con la interpretación de la Corte Suprema de Justicia estadounidense las personas jurídicas son consideradas como "personas" (Pembina Consolidated Silver Mining Co. v. Pennsylvania, 125 U.S. 181, 1888). No obstante la idea de que una corporación puede sufrir un disturbio emocional es las cortes no la han apoyado. En su lugar, la discusión se centra en la posibilidad que tienen las compañías de demandar por difamación. A pesar de que una empresa no tiene, en el sentido personal de la palabra, una reputación (Prosser, 1971, p. 745) ésta llega a establecer, en el transcurso común de sus negocios, un cierto nivel de credibilidad y respeto y se constituye un interés que se debe proteger y que impacta la forma como el público la percibe. ${ }^{22}$

La ley considera a la corporación como un individuo independiente de sus miembros; por lo que un ataque a los miembros de la corporación no le da a ésta una acción válida para reclamar compensación por la difamación. Otro punto importante es que debido a que las personas jurídicas no puedensentir emociones deben probar que sufrieron un daño pecuniario. ${ }^{23}$

Una discusión más reciente se centra en el uso que le dan las compañías a su derecho demandar por difamación ya que existe una tendencia a usar estas acciones para atacar críticas válidas. Estas demandas reciben el nombre de Slapps -Strategic Lawsuit Against Public Participation- (Demandas estratégicas contra la participación pública) Por definición las Slapps son acciones carentes de

\footnotetext{
19 Ídem.

${ }^{20}$ Scandalum Magnatum: discurso difamatorio o escrito publicado con el afán de ofender al otro, un juez o cualquier otra autoridad de Inglaterra.

(https://www.merriamwebster.com/dictionary/scandalum\%20magnatum) recuperado el 16 de febrero de 2019.

${ }^{21}$ Op cit nota 36, ídem.

${ }^{22}$ Op cit, nota 36, pag.637

${ }^{23}$ Ídem
} 


\section{El daño moral como parte de la responsabilidad civil en el Derecho Internacional Privado}

Año 11, Número 20 enero-junio 2019

Eusebio Francisco Tulio Flores Contreras

méritos que persiguen castigar a las personas por ejercer sus derechos y evitar que los intereses de la empresa se vean afectados. ${ }^{24}$

Los sistemas del Common Law y los derechos continentales de origen romano germánico en materia de responsabilidad civil tienen muchos puntos análogos, muchos más de los imaginables a priori.

Los "non pecuniary loss" son una clase de daños cuya recepción fue objeto de reparos por sectores de la doctrina y la jurisprudencia, pero hoy se encuentra superada la problemática que siguió a su aparición como categoría a indemnizar en el Common Law. Sin duda el aspecto más difícil para la asimilación de esta clase de daños fue el más criticado, cual es el conflicto en el establecimiento de la indemnización. La subjetividad tácita que conlleva su estimación, que carece además de un fin restitutorio indiscutible, representa la más grande dificultad en su mensura y singularización en dinero. Se agrava esto último en el Common Law, ya que al ser esta fijada por el jurado, la sentencia solo será apelable si la indemnización es demasiado alta o baja. ${ }^{25}$

No es en consecuencia de extrañar que no exista hoy una definición de "non pecuniary loss". Esto pese a ser un concepto transversal al ordenamiento de los países del Common Law. Se le puede encontrar asociado a la salud de una persona, pasando desde indemnizaciones en incumplimientos contractuales a derechos de marcas y derechos de propiedad e incluso por responsabilidad en caso de detenciones ilegítimas, entre otros. ${ }^{26}$

Los dos principales grupos de "non pecuniary loss" en la ley inglesa son: "pain and suffering" y el "loss of amenities". En lo que a daños corporales se refiere sí es posible distinguir un tercer grupo llamado "loss of expectation of life", que ha sido asimilado a los ya mencionados grupos principales, pese a que en Australia y en Irlanda aún recibe un tratamiento diferenciado. ${ }^{27}$

Esta es una nomenclatura adoptada por el sistema legal en su conjunto, usada indistintamente por jueces, abogados y la doctrina. Presenta la misma dificultad, tantas veces comentada en el sistema romano germánico, cual es la existencia de indemnizaciones globales. En el Common Law existe el principio de reparación integral de los daños y perjuicios, principio que recibe la denominación de "fairness" 28. En Inglaterra en lo que a perjuicios patrimoniales se refieren los jueces desarrollan el concepto comprendiendo en él cualquiera de las derivaciones del hecho dañoso. Esto se justifica porque la prueba de su cuantía no es problemática y más bien determinable. No ocurre lo mismo en el tema de los daños morales: Ios resarcimientos acostumbran a no cubrir la totalidad de lo demandado, al estar sujetos a la independiente valoración de los tribunales, sin elementos que puedan llevar a su ponderación de manera comprensible las más de las veces, lo

\footnotetext{
${ }^{24}$ Ídem

${ }^{25}$ Barrientos Zamorano, Marcelo. Daño extrapatrimonial o moral por actuación de una autoridad: su valoración y prueba, Revista Sentecias Dictadas, No. 2011, Chile, 2011. Pág. 246

${ }^{26}$ Ídem

${ }^{27}$ Ídem pag. 247
} 
que arroja habitualmente indemnizaciones colectivas o en globo por todos los perjuicios, sean estos patrimoniales o extrapatrimoniales ${ }^{28}$

Hoy prima sobre lo anteriormente señalado un verdadero catálogo de daños llamado en inglés "general damages" y dentro de él, daños morales o extrapatrimoniales producto de un perjuicio de carácter personal. Una manera de conocer la realidad que se presenta en Inglaterra es a través del informe "Guidelines for the Assesment of General Damages in Personal Injuries Cases". Es posible constatar que no hay grandes diferencias entre el sistema inglés y el escocés30. Como asimismo se comprueba que es Irlanda, con distancia, la que posee dentro del Common Law una actitud más a favor de la víctima. ${ }^{29}$

Descendiendo a un detalle mayor del sistema inglés, en él se distinguen dos supuestos. Si el trastorno es consecuencia de un daño a la integridad física, la pena y el sufrimiento propios de la lesión, estos se indemnizarán en la compensación de los tipos de daño moral que normalmente derivaban de la lesión física, que son: "pain and suffering" y, cuando la situación lo exige, "loss of amenities". Si es un daño psíquico autónomo, al margen de cualquier lesión corporal, se admite su indemnización, siempre que pueda calificarse como enfermedad psiquiátrica, siendo insuficiente la simple preocupación o pena. ${ }^{30}$

Dentro del concepto del "loss of amenity", encontramos la merma de goces vitales o de facultades que imposibilitan a la víctima efectuar actividades de agrado a las que antes estaba habituado. Incluido dentro de los "non pecuniary loss", es usual en la legislación del Common Law que una misma suma sea destinada a "loss of amenity" y "pain and suffering", pero académicamente se separa para su mejor comprensión. Es un concepto que varía de acuerdo a la expectativa de vida de la persona. ${ }^{31}$

En consecuencia, los "non pecuniary loss" no son diferenciados ni razonados en las sentencias, simplemente se otorgan. Nadie sabe a cuánto ascenderá un "pan and suffering" y a cuánto un "loss of amenity". Los criterios en tal sentido parecen estar en directa relación con la pérdida patrimonial y en cuanto al monto patrimonial de la indemnización, con el daño físico o mental producido o probado y demandado. Es decir, es un complemento de otras partidas de la indemnización. ${ }^{32}$

El impacto nervioso ha de jugar un rol fundamental. Las cortes inglesas han pretendido dotar al término "nervous schock" de un contenido que se acerque al de daño en términos científicos. De esta forma se ha comenzado a llamarle más bien como "psychiatric damage" e incluso "psychiatric illness". Se ha argumentado que la expresión "nervous schock" se presta a malentendidos e imprecisiones. "Psychiatric damage" comprende mejor la enfermedad mental, la neurosis y el cambio en la personalidad que se produce en el sujeto que lo padece. ${ }^{33}$

\footnotetext{
${ }^{28}$ Idem

${ }^{29}$ Ídem pag. 248

30 Ídem

31 Ídem

32 Ídem pags. 248-249

33 ídem
} 


\section{El daño moral como parte de la responsabilidad civil en el Derecho Internacional Privado}

Año 11, Número 20 enero-junio 2019

Eusebio Francisco Tulio Flores Contreras

En el Common Law se ha tratado de determinar jurisprudencialmente cuál debe ser la forma mínima de un trastorno psíquico para que sea objeto de indemnización. La tarea de la justicia entonces ha consistido en determinar un límite que lleve a escoger demandas que no sean temerarias, evitando con ello una saturación del sistema judicial por la presentación de trastornos nerviosos insignificantes, simples angustias, ansiedades menores o zozobras que pueden ser considerados normales, y por lo tanto, que no caerían en la categoría de "nervous shock cases" o más correctamente y siguiendo la nomenclatura inglesa actual: "positive psychiatric illness" . ${ }^{34}$

Los elementos que la Corte toma en cuenta en la configuración de estas categorías de "non pecuniary loss" son las privaciones físicas y síquicas que la víctima padece a consecuencia del daño, el llamado "the bodily injury sustained"

El dolor de la víctima siempre jugará un rol, porque la demanda es personal y en un caso de "non pecuniary loss", teóricamente estamos ante dos supuestos: "pain and suffering" y "loss of amenity". El primero es importante e independiente en dos tipos de casos: a) en el evento de que la víctima pueda demostrar que padece o padeció un tipo de daño y esto le produjo un estrés mental acorde con el daño, y; b) en la hipótesis de que el daño sea menor del que se ha demandado, ya que son menores los casos en que las víctimas sufren daños que no signifiquen una pérdida, por ejemplo, en medio de una cirugía consentida y con anestesia. La distinción es útil porque explica el porqué la víctima que no está en estado comatoso siempre obtiene mayores indemnizaciones en el sistema inglés, ya que el elemento de "loss of amenity" es el más importante en la indemnización en estos casos. No obstante, la falta de conciencia y de capacidad sensitiva hacen imposible la indemnización por el dolor y el sufrimiento padecidos, es decir el "pain and suffering" 35

Gran parte de los Estados de EE.UU, han establecido un límite al monto que puede ser otorgado en concepto de daño no económico, aunque en algunos casos este límite ha sido declarado ilegal o inconstitucional. Las cortes de Alabama, Georgia, Missouri, North Dakota, Washington and Oregón declararon el límite inconstitucional por violar el derecho a un juicio por jurado (American Medical Association, 2012a,2012b). En Illinois el límite fue revocado porque las cortes consideraron que violaba la separación de poderes (American Medical Association, 2012a, 2012b). Y en New Hampshire se revocó porque violaba la cláusula de protección igualitaria (American Medical Association, 2012a, 2012b). En el caso de Missouri, los límites fueron revocados mediante una ley especial (American Medical Association, 2012a, 2012b). ${ }^{36}$

Los estados de Alaska, California, Colorado, Florida, Idaho, Indiana,Kansas, Louisiana, Maryland, Michigan, Nebraska, Nuevo México, Ohio,Oklahoma, Texas, Utah, Virginia, Virginia del Oeste y Wisconsin tienen leyes que limitan el montoque puede darse como compensación. En Oklahoma, Wisconsin, Texas y Ohio las cortes abolieron las leyes que establecían estos límites, pero desde entonces

\footnotetext{
${ }^{34}$ Ídem

35 Ídem pag. 250

${ }^{36}$ Op cit nota 36 pags. $639-640$
} 
nuevas leyes han sido promulgadas y éstas aún no han sido derogadas o abolidas (American Medical Association,2012a, 2012b). ${ }^{37}$

\section{El daño moral en Arizona y California, su adecuación legal.}

Siendo dos de los Estados de EE.UU que tienen una cercanía no solamente territorialmente hablando, sino también en cuanto a lo que a la historia atañe, veamos cómo es que se encuentra regulado el daño moral en éstos.

\section{Arizona. ${ }^{38}$}

En Arizona los daños por "pain and suffering" comprenden muchos supuestos, que incluyen.

- Despido injustificado

- Accidentes automovilísticos

- Daño a la reputación

- Incumplimiento de contrato (circunstancias limitadas)

- Productos defectuosos

- Resbalar y caer ( Ilamada en inglés "slip and fall")

- Muerte injusta

- Negligencia médica

- Lesión intencional (agravio intencional)

Arizona tiene límites de tiempo o " Statutes of limitations " sobre la prescripción para presentar una demanda por "pain and suffering" (daños y perjuicios). Si bien tiene doce años impresionantemente largos para presentar una reclamación de responsabilidad civil por fallas en productos, la mayoría de las reclamaciones por daños morales deben presentarse dentro de los dos años posteriores a la lesión. Si está tratando de obtener una indemnización de un daño moral derivado de un falso encarcelamiento, daño a la reputación, despido injustificado o incumplimiento de la reclamación del contrato, no tiene tiempo que perder: debe presentarla en tan solo un año.

Arizona no es diferente de la mayoría de los estados de EE.UU en que no ofrece daños por "pain and suffering" como parte de los daños por reclamos de compensación de un trabajador. Sin embargo, si su reclamo se deriva de uno de

\footnotetext{
37 Ídem

${ }^{38}$ https://statelaws.findlaw.com/arizona-law/pain-and-suffering-damages-in-arizona.html (recuperado el día 17 de febrero de 2019)
} 


\section{El daño moral como parte de la responsabilidad civil en el Derecho Internacional} Privado

Año 11, Número 20 enero-junio 2019

Eusebio Francisco Tulio Flores Contreras

los muchos reclamos que permiten "pain and suffering", en Arizona no hay límites impuestos por el estado sobre la cantidad que el jurado puede otorgarle.

\section{California ${ }^{39}$}

En California, los daños por "pain and suffering" están disponibles como parte de la categoría más amplia de "daños no económicos" que incluye:

- Sufrimiento mental

- Estrés emocional

- Pérdida de la sociedad y compañerismo.

- Lesión a la reputación

- Humillación

- Accidentes automovilísticos

- Productos defectuosos

- Resbalar y caer

- Negligencia médica

A diferencia de la mayoría de los Estados de EE.UU, la Ley de California establece que los tribunales deben usar la regla de "pure comparative fault" para determinar la responsabilidad por daños no económicos. Esto quiere decir que si el Tribunal determina que usted fue más responsable de su accidente que cualquier otra parte, aún puede recibir una cantidad proporcional de daños y perjuicios. Por poner un ejemplo, digamos que un Tribunal determina que usted fue responsable en un $70 \%$ por su lesión. Si la corte le otorgó \$100,000 en daños no económicos, la corte reduciría su indemnización por daños, pero aún podría recibir $\$ 30,000$ en daños no económicos.

En California, si el daño es resultado de un accidente automovilístico, un incidente de resbalones y caídas (slip and fall), cualquier otro acto negligente de otra persona o el resultado de un acto intencional, se requiere que presente su demanda dentro de los dos años posteriores al incidente. Para casos de negligencia médica, debe presentar su demanda dentro de un año después de descubrir la lesión o tres años después de la fecha de la lesión, lo que ocurra primero.

\section{TRATADOS INTERNACIONALES DE DERECHOS HUMANOS}

Dentro nuestra legislación local y federal existen normas relativas a los Derechos Humanos, mismas que han establecido comisiones encaminadas a la protección y salvaguarda de éstos, sin embargo en este bloque pretendemos darle un espacio Internacional comparatista.

Actualmente, todo profesionista y operador jurídico debe observar los tratados internacionales. Ya no se trata de algo lejano que no se pueda aplicar a un

\footnotetext{
${ }^{39}$ https://statelaws.findlaw.com/california-law/pain-and-suffering-damages-in-california.html (recuperado el17 de febrero de 2019)
} 
caso en concreto, si no que por el contrario y a raíz de la de reforma constitucional de 10 de junio 2011, debemos conocer sobre los tratados internacionales en los que México sea parte.

Es por ello que en este apartado, procederemos a estudiar aquellos que nos puedan aportar algo significativo para nuestro tema de estudio.

Declaración Universal de los Derechos Humanos.

Proclamada el 10 de diciembre de 1948, en la Asamblea General de Naciones de París, es un documento que cambió al mundo, pues esta fue la daría la pauta para la elaboración de tratados internacionales en materia de derechos humanos. ${ }^{40}$

"Artículo 3.

Todo individuo tiene derecho a la vida, a la libertad y a la seguridad de su persona."

"Artículo 8.

Toda persona tiene derecho a un recurso efectivo ante los tribunales nacionales competentes, que la ampare contra actos que violen sus derechos fundamentales reconocidos por la constitución o por la ley." "Artículo 12.

Nadie será objeto de injerencias arbitrarias en su vida privada, su familia, su domicilio o su correspondencia, ni de ataques a su honra o a su reputación. Toda persona tiene derecho a la protección de la ley contra tales injerencias o ataques."

\section{Pacto Internacional de los Derechos Civiles y Políticos.}

Pacto que fue adherido por México el 24 de Marzo de 1981, en el sexenio de José López Portillo, dicho tratado tomo lineamientos establecidos en la Declaración Universal de Derechos Humanos, para reforzarlos y ampliarlos en lo que atañe a la persona. 41

"Artículo 2.

3. Cada uno de los Estados Partes en el presente Pacto se compromete a garantizar que:

a) Toda persona cuyos derechos o libertades reconocidos en el presente Pacto hayan sido violados podrá interponer un recurso efectivo, aun cuando tal violación hubiera sido cometida por personas que actuaban en ejercicio de sus funciones oficiales..."

\section{“Artículo 19.}

\footnotetext{
${ }^{40} \mathrm{http}$ ://www.un.org/es/universal-declaration-human-rights/ (recuperado el 20 de Noviembre de 2018).

${ }^{41}$ https://www.colmex.mx/assets/pdfs/2-PIDCP 49.pdf?1493133879 (recuperado el 20 de Noviembre de 2018)
} 


\section{El daño moral como parte de la responsabilidad civil en el Derecho Internacional Privado \\ Año 11, Número 20 enero-junio 2019 \\ Eusebio Francisco Tulio Flores Contreras}

2. Toda persona tiene derecho a la libertad de expresión; este derecho comprende la libertad de buscar, recibir y difundir informaciones e ideas de toda índole, sin consideración de fronteras, ya sea oralmente, por escrito o en forma impresa o artística, o por cualquier otro procedimiento de su elección.

3. El ejercicio del derecho previsto en el párrafo 2 de este artículo entraña deberes y responsabilidades especiales. Por consiguiente, puede estar sujeto a ciertas restricciones, que deberán, sin embargo, estar expresamente fijadas por la ley y ser necesarias para:

a) Asegurar el respeto a los derechos o a la reputación de los demás;

b) La protección de la seguridad nacional, el orden público o la salud o la moral públicas."

\section{Convención Americana sobre Derechos Humanos.}

Conocida también como Pacto de San José de Costa Rica, fue firmada el 22 de Marzo de 1969, misma que se adhería México hasta el año de 1981, tiene como propósito de consolidar en el continente americano, dentro del cuadro de las instituciones democráticas, un régimen de libertad personal y de justicia social, fundado en el respeto de los derechos esenciales del hombre..$^{42}$

"Artículo 4. Derecho a la Vida

1.Toda persona tiene derecho a que se respete su vida. Este derecho estará protegido por la ley y, en general, a partir del momento de la concepción. Nadie puede ser privado de la vida arbitrariamente."

"Artículo 5. Derecho a la Integridad Personal

1. Toda persona tiene derecho a que se respete su integridad física, psíquica y moral."

"Artículo 7. Derecho a la Libertad Personal

1. Toda persona tiene derecho a la libertad y a la seguridad personal."

"Artículo 11. Protección de la Honra y de la Dignidad

1. Toda persona tiene derecho al respeto de su honra y al reconocimiento de su dignidad.

\footnotetext{
${ }^{42}$ https://www.colmex.mx/assets/pdfs/4-CADH 51.pdf?1493133911 (Recuperado el 22 de Noviembre de
} 
2. Nadie puede ser objeto de injerencias arbitrarias o abusivas en su vida privada, en la de su familia, en su domicilio o en su correspondencia, ni de ataques ilegales a su honra o reputación.

3. Toda persona tiene derecho a la protección de la ley contra esas injerencias o esos ataques."

\section{"Artículo 25. Protección Judicial}

1. Toda persona tiene derecho a un recurso sencillo y rápido o a cualquier otro recurso efectivo ante los jueces o tribunales competentes, que la ampare contra actos que violen sus derechos fundamentales reconocidos por la Constitución, la ley o la presente Convención, aun cuando tal violación sea cometida por personas que actúen en ejercicio de sus funciones oficiales."

\section{Corte Interamericana de Derecho Humanos, sus criterios en cuanto al daño moral.}

Hemos elegido a la Corte Interamericana de Derechos Humanos, no solo por la cercanía geográfica que existe entre nuestro país y su sede, San José de Costa Rica. Sino que México formado parte de diversos litigios que han marcado precedentes en dicho Tribunal internacional.

Dicho lo anterior, enlistar los criterios que ha establecido la Corte, da para sí, un trabajo de gran extensión. Es por ello, que tomaremos en específico un caso, resaltando los puntos que más atañen a nuestro tema.

Caso Tibi vs Ecuador (7 de septiembre de 2004).

El 27 de septiembre de 1995 agentes de la INTERPOL del Guayas, detuvieron al señor Daniel Tibi, quien era un ciudadano francés de 36 años que residía en Ecuador y se dedicaba al comercio de piedras preciosas y arte ecuatoriano. Dicha detención se realizó porque Daniel Tibi estaba presuntamente involucrado en el comercio de droga.

Al momento de su arresto, los policías no le comunicaron los cargos en su contra. Como excusa le dijeron que se trataba de un "control migratorio". El señor Tibi permaneció bajo detención preventiva, en forma ininterrumpida, en centros de detención ecuatorianos, desde el 27 de septiembre de 1995 hasta el 21 de enero de 1998, cuando fue liberado.

El señor Daniel Tibi fue objeto de actos de tortura y amenazado, por parte de los guardias de la cárcel, con el fin de obtener su autoinculpación. En la cárcel el señor Daniel Tibi fue examinado dos veces por médicos ecuatorianos designados por el Estado. Estos verificaron que sufría de heridas y traumatismos, pero nunca recibió tratamiento médico ni se investigó la causa de sus padecimientos. Durante su detención interpuso dos recursos de amparo y una queja, los cuales no prosperaron. 


\section{El daño moral como parte de la responsabilidad civil en el Derecho Internacional Privado}

Año 11, Número 20 enero-junio 2019

Eusebio Francisco Tulio Flores Contreras

Dentro del presente Caso en estudio, la Corte sostuvo lo siguiente:

"El daño inmaterial puede comprender tanto los sufrimientos y las aflicciones causados a las víctimas directas y a sus allegados, como el menoscabo de valores muy significativos para las personas, así como las alteraciones, de carácter no pecuniario, en las condiciones de existencia de la víctima o su familia. Por cuanto no es posible asignar al daño inmaterial un preciso equivalente monetario, sólo puede ser objeto de compensación, en dos formas. En primer lugar, mediante el pago de una cantidad de dinero o la entrega de bienes o servicios apreciables en dinero, que el Tribunal determine en aplicación razonable del arbitrio judicial y en términos de equidad. $Y$, en segundo lugar, mediante la realización de actos u obras de alcance o repercusión públicos, tales como la transmisión de un mensaje de reprobación oficial a las violaciones de los derechos humanos de que se trata y de compromiso con los esfuerzos tendientes a que no vuelvan a ocurrir, que tengan como efecto, entre otros, el reconocimiento de la dignidad de la víctima.

La jurisprudencia internacional ha establecido reiteradamente que la sentencia constituye per se una forma de reparación. No obstante, tomando en cuenta las circunstancias del presente caso, la intensidad del sufrimiento que los hechos causaron a las víctimas, las alteraciones de sus condiciones de existencia y las demás consecuencias de orden no material o no pecuniario que sufrieron éstos, la Corte estima pertinente ordenar el pago de una compensación por concepto de daños inmateriales, conforme a la equidad.

Al fijar la compensación por daño inmaterial en el caso sub judice, se debe considerar que Daniel Tibi fue sometido a condiciones de reclusión inhumanas y fue torturado, lo cual le produjo intensos dolores corporales, sufrimientos y quebrantos emocionales, así como consecuencias físicas y psicológicas que aún perduran. Además, las actuaciones que se siguieron en su contra no cumplieron con los requisitos del debido proceso (hubo detención ilegal y arbitraria, falta de garantías judiciales y de protección judicial). Naturalmente, la persona sometida a detención arbitraria experimenta un profundo sufrimiento, que se agrava si se toma en cuenta que no se han investigado los hechos relacionados con la tortura de que fue objeto la víctima. Este Tribunal considera que se presume que las violaciones de esta naturaleza causan daños inmateriales a quien las padece..."

${ }^{43}$ http://www.corteidh.or.cr/docs/casos/articulos/seriec 114 esp.pdf (recuperado el 26 de febrero de 2019) 


\section{Caso Aloeboetoe y otros Vs. Surinam (10 de septiembre de 1993)}

El 31 de diciembre de 1987 en Brokopondo. Aproximadamente 20 personas se encontraban por dicha zona a fin de regresar a sus hogares luego de haber estado en la ciudad de Paramaribo. Elementos de las fuerzas armadas detuvieron a éstas últimas, bajo la sospecha de que eran miembros del Comando de la Selva y posteriormente fueron golpeados con las culatas de las armas de fuego de los soldados. Algunos de ellos fueron heridos gravemente con bayonetas y cuchillos. Les obligaron a acostarse boca abajo en el suelo y los militares les pisaron la espalda y los orinaron.

Poco después, los militares permitieron que las personas prosiguieran su viaje con excepción de siete: Daison Aloeboetoe, Dedemanu Aloeboetoe, Mikuwendje Aloeboetoe, John Amoida, Richenel Voola, Martin Indisie Banai y Beri Tiopo. Ellos fueron arrastrados con los ojos vendados al interior de un vehículo militar y llevados rumbo a Paramaribo.

Antes de llegar a Paramaribo, el vehículo se detuvo y los militares ordenaron a las víctimas que salieran de él; a las que no lo hicieron las sacaron a la fuerza. Se les dio una pala y a poca distancia del camino se les ordenó que comenzaran a excavar. Richenel Voola trató de escapar pero los militares dispararon contra él. Poco tiempo después las otras seis personas fueron asesinadas por los militares.

En relación con lo anterior, la Corte afirmó lo siguiente:

"El daño moral infligido a las víctimas, a criterio de la Corte, resulta evidente pues es propio de la naturaleza humana que toda persona sometida a las agresiones y vejámenes mencionados experimente un sufrimiento moral. La Corte estima que no se requieren pruebas para llegar a esta conclusión y resulta suficiente el reconocimiento de responsabilidad efectuado por Suriname en su momento.

En cuanto a la reparación por daño moral, la Corte considera que, habida consideración de la situación económica y social de los beneficiarios, debe otorgarse en una suma de dinero que debe ser igual para todas las víctimas, con excepción de Richenel Voola, a quien se le asignó una reparación que supera en un tercio a la de los otros. Como ya se ha señalado esta persona estuvo sometida a mayores padecimientos derivados de su agonía. No existen en cambio elementos para suponer que haya habido diferencias entre las injurias y malos tratos de que fueron objeto las demás víctimas. 92. A falta de otros elementos y por considerarlo equitativo la Corte ha tomado el monto total reclamado por la Comisión por daño moral." 44

\footnotetext{
${ }^{44}$ http://www.corteidh.or.cr/docs/casos/articulos/seriec 15 esp.pdf (recuperado el 27 de febrero de 2019)
} 


\section{El daño moral como parte de la responsabilidad civil en el Derecho Internacional Privado}

Año 11, Número 20 enero-junio 2019

Eusebio Francisco Tulio Flores Contreras

\section{CONCLUSIONES Y RECOMENDACIONES}

Como se estableció desde un principio, el origen del daño moral como institución jurídica resulta algo ambiguo. Desde la injuria de los romanos hasta la "moderna" definición consagrada en nuestro actual Código Civil, el concepto del daño moral ha estado en constante cambio, lo cual es sumamente entendible. El pensamiento del ser humano, sus creencias, dogmas, ideales percepciones, han cambiado y seguirán cambiando de forma radical. Lo cual nos lleva a entender que, las definiciones que existen hoy pueden ser otra cosa diversa mañana.

Si bien cierto es que, hoy en día en nuestro país existe un panorama legislativo amplísimo en relación al tema de estudio de este trabajo, tal como lo analizamos al abordar diversas legislaciones nacionales, hace falta que estas desarrollen más su apartado respecto a la cuantificación del daño como tal. No halando en el sentido de establecer lineamientos o parámetros que sirvan como una "formula" o "regla", ya que esto es imposible, pues recordemos que el daño moral es un tema evidentemente subjetivo.

Lo anterior nos lleva a que los actuales factores de cuantificación del daño moral, deben ser desarrollados de una forma más precisa. Necesariamente tienen que ser aterrizados en conjunción con la jurisprudencia, ya esta última ha cumplido con la función de interpretarlos.

Por otro lado, retomando el análisis comparativo que realizamos con diversos países, rescatamos que en cuanto la definición del daño moral puede ser muy similar en otros países, pues todos los conceptos que analizamos tienen rasgos semejantes. Sin embargo, no sucede esto a la hora de la determinación del daño o su cuantificación. Difícil sería encontrar en este sentido una armonía de raciocinio judicial, pues es de entenderse que el contexto en el que se desarrolla cada definición del daño moral es distinto. Un Juez argentino no juzgaría de la misma manera que un Juez cubano, pues sus criterios, experiencia, etc, es diferente uno del otro.

En otro aspecto, cabe resaltar la importancia que juegan los tratados internacionales en el ámbito jurisdiccional, más en tiempos actuales en los que los derechos humanos son el tema de discusión de día con día. Es por ello que el juez no se debe de limitar al marco nacional, sino que debe ver con que otros medios o instrumentos internacionales se puede ayudar para cumplir con esa facultad solemne que le fue concedida por el Estado: la impartición de justicia.

Es por ello que el daño moral como parte de la responsabilidad civil debe ser algo que este en constante análisis, no solo en el marco jurídico nacional, sino también en otros países. Lo anterior con el objetivo de observar de qué forma se está analizando a la "moral" y a la "moralidad", ya que esto nos permitirá comprender el cambio constante del pensamiento del ser humano, pues recordemos que nuestro tema de estudio es algo meramente subjetivo, lo que lo lleva a ser una variante y no una constante. 
FUENTES BIBLIOGRÁFICAS.

BARRIENTOS ZAMORANO, Marcelo. Daño extrapatrimonial o moral por actuación de una autoridad: su valoración y prueba, Revista Sentecias Dictadas, No. 2011, Chile, 2011

BEJARANO, SÁNCHEZ, M. Obligaciones Civiles, Ed. Oxford, Quinta edición, México, 1999

BONNECASE, Julien, Tratado de Derecho Civil, Tomo I, Ed. Harla, México, 1997.

BORJA, SORIANO, M. Teoría General de las Obligaciones, Ed. Porrúa, Décima Octava edición, México, 2001

FLORES, Eusebio, Prontuario General de Derecho Romano, Ed. Cárdenas Editor y Distribuidor, 1ra edición, México, 1991

FLORIS, MARGADANT S, G. El Derecho Privado Romano, Ed. Esfinge, Vigésima Cuarta edición, México, 1999

GARCIA SAAVEDRA, José D et al. Diccionario Jurídico Mexicano, Ed. Pearson, 1a. Ed, México, 2012Goodwin (1989) "Theories of compensation, "Oxford Journal of Legal Studies.

GUTIÉRREZ ALVIZ Y ARMANIO, Faustino, Diccionario de Derecho Romano, Reus, Madrid, 1982.

GUTIÉRREZ Y GONZÁLEZ, E. Derecho de las obligaciones, Ed. Porrúa, decima séptima edición, México, 2008.

LÓPEZ SÁNCHEZ, C., "La indemnización del daño moral derivado de la infracción de derechos de propiedad intelectual e industrial", en Problemática actual de la tutela civil ante la vulneración de la propiedad industrial e intelectual, coord. J.A. Moreno Martínez, Dykinson, Madrid, 2017

MARTíNEZ ALFARO, Joaquín. Teoría de las Obligaciones, Ed. Porrúa, 11va ed, México, 2008

MARTÍN-CASALS, Miquel (1990) "Notas sobre la indemnización del daño moral en las acciones por difamación de la LO 1/1982", en Asociación de Profesores de Derecho Civil, Centenario del Código Civil (1889-1989), tomo II, CEURA, Madrid

MAZEAUD, H, J. Lecciones de Derecho Civil, parte segunda, Volumen II, "La Responsabilidad Civil y los Cuasicontratos" Ed. Ediciones Jurídicas EuropaAmérica, Buenos Aires, 1960

OCHOA OLVERA, Salvador. "La demanda por daño moral" Ed. Monte Alto" México, 1993.

PETIT, EUGÈNE. Tratado Elemental de Derecho Romano, Ed. Porrúa, Onceava edición, México, 1994

RECASENS, SICHES, L. Filosofía del Derecho, Ed. Porrúa, Décima Octava edición, México, 2006 Revista de Derecho Privado, Instituto de Investigaciones Jurídicas de la Universidad Nacional Autónoma de México. Cuarta Época, Julio-Diciembre de 2012.

RODRÍGUEZ, SAMUDIO, R. El Daño no económico en el Derecho Estadounidense, Revista Facultad de Derecho y Ciencias Politicas, Vol. 44, No. 121, JulioDiciembre, 2014. Medellín, Colombia

SCHULZ, FRITZ, Derecho Romano Clásico, Ed. BOSCH, Primera Edición, Barcelona, 1960

KÖNDGEN, W. (1976): Haftpflichfunktionen und Immaterialschaden am Beispiel von Schmerzensgeld bei Gefährdungshaftung "Funciones de responsabilidad civil 
y daños materiales en el ejemplo de compensación por dolor y sufrimiento" (Berlin, Duncker und Humblot).

JÜLICH, H. (1978): Die Funktion des Schmerzensgeldes "La Función del Dolor" (Saarbrücken, Dissertation)

\section{Legislación Nacional.}

- Código Civil para el Estado de Sonora.

- Código Civil Federal.

- Código Civil para el Estado de Nuevo León

- Ley de Responsabilidad Civil para la Protección del Derecho a la Vida Privada, el Honor y la Propia Imagen en el Distrito Federal.

- Ley Federal de Protección al Consumidor.

- Ley de la Propiedad Industrial.

- Ley Federal de Telecomunicaciones y Radiofusión.

- Ley para la Protección de Personas Defensoras de Derechos Humanos y Periodistas.

- Ley Federal para Prevenir y Eliminar la Discriminación.

Legislación Internacional.

- Código Civil Francés.

- Código Civil de la República Argentina.

- Código Civil Cubano.

- Código Civil de Quebec.

\section{Tratados Internacionales.}

- Declaración Universal de los Derechos Humanos.

- Pacto Internacional de los Derechos Civiles y Políticos

- Convención Americana sobre Derechos Humanos.

\section{Jurisprudencia Nacional.}

- DAÑo MORAL. El juzgador civil al estimarlo acreditado con motivo de la prueba del hecho ilícito, debe resolver sobre la indemnización que corresponda, independientemente de que no se acredite el monto exacto reclamado (legislación del estado de méxico), 10a. Época; T.C.C.; Gaceta S.J.F.; Libro 26, Enero de 2016; Tomo IV; Pág. 3185. II.40.C.18 C (10a.).

- DAÑO MORAL. ES LA ALTERACIÓN PROFUNDA QUE SUFRE UNA PERSONA EN SUS SENTIMIENTOS, AFECTOS, CREENCIAS, DECORO, HONOR, REPUTACIÓN, VIDA PRIVADA, CONFIGURACIÓN Y ASPECTOS FÍSICOS, O BIEN, EN LA CONSIDERACIÓN QUE DE SÍ MISMA TIENEN LOS DEMÁS, PRODUCIDA POR HECHO ILÍCITO, 10a. Época; T.C.C.; S.J.F. y su Gaceta; Libro IV, Enero de 2012; Tomo 5; Pág. 4036. I.3o.C. J/71 (9a.).

- dAÑO mORAL. REQUisitos nECESARIOS PARA QUE PROCEDA SU REPARACIÓN, 8a. Época; T.C.C.; Gaceta S.J.F.; Núm. 85, Enero de 1995; Pág. 65. I.5०.C. J/39.

- DAÑO moral. LAS PERSONAS MORALES ESTÁN LEGITIMADAS PARA DEMANDAR SU REPARACIÓN EN CASO QUE SE AFECTE LA CONSIDERACIÓN QUE TIENEN LOS DEMÁS RESPECTO DE ELLAS (ARTÍCULO 1916 DEL CÓDIGO CIVIL PARA EL DISTRITO FEDERAL)." 